\title{
Regeneration of a Distinctive Set of Axosomatic Contacts in the Leech Central Nervous System
}

\author{
Kathleen A. French* and Kenneth J. Muller ${ }^{\star}$ \\ *Department of Embryology, Carnegie Institution of Washington, Baltimore, Maryland 21210, and \\ tDepartment of Physiology and Biophysics, University of Miami School of Medicine, Miami, Florida 33101
}

\begin{abstract}
The nociceptive sensory neurons ( $\mathrm{N}$ cells) in the lecch Hirudo medicinalis contact other neurons through conventional synapses in the neuropile and through baskets of processes that wrap the somata of particular cells. These axosomatic contacts are made with the pressure $(P)$ and $N$ sensory neurons in the adjacent segmental ganglia, but not with cells within the same ganglion as the wrapping cell. Physiological evidence indicates that these contacts may be synaptic, although conventional synapses have not been observed with electron microscopy.

After they have been injured, lateral $\mathbf{N}$ cell processes can grow into the anterior adjacent ganglion and regenerate somatic contacts. In general, regenerated $\mathbf{N}$ cell processes wrap the same somata as do intact $\mathbf{N}$ cells, but they often wrap fewer somata. However, six of 14 regenerated $N$ cells also wrapped the soma of a small posterior cell that was contacted in only one of 120 normal ganglia examined. It thus appears that the growing processes of an injured $\mathbf{N}$ cell select certain cell somata to wrap, but that the selection is somewhat broader than that in the embryonic leech.
\end{abstract}

Growing axons typically choose to connect with only certain cells, while rejecting others. In many species such selective connections are made not only during embryonic development, but also when axons regenerate after injury. Specific reconnection between single neurons was first demonstrated in the leech, where mechanosensory neurons in the CNS were shown physiologically to reestablish contact with neurons that are their normal synaptic targets (Baylor and Nicholls, 1971; Jansen and Nicholls, 1972). Even in the leech, however, it has been difficult to determine how completely and accurately axons restore their normal pattern of connections. Are all of the usual targets contacted? Are inappropriate or abnormal contacts made? Is the final pattern of connections the result of a paring of excess conlacts, as can occur during development? Answering these questions should reveal much about the capabilities of regenerating axons and the degree to which regeneration may recapitulate aspects of embryonic development.

In the leech, many of the connections that mechanosensory neurons make with some of the 400 neurons in each of the adjacent ganglia are known and offer a valuable baseline for the analysis of regeneration. Nonetheless, no cell's complete pattern of connectivity is known. Electrophysiological investigations are constrained by the number of cells that can be penetrated with

\footnotetext{
Received Apr. 24, 1985 ; revised June 28, 1985 ; accepted July 2, 1985.

This work was supported in part by National Institutes of Health Grants NS15014 and NS20607 and a McKnight Neurosciences Development award to K.J.M. We thank Ellen J. Elliott, Sheryl A. Scott, and Barbara E. Thomas for their contributions to the early stages of this work, and William B. Kristan, Jr., Ellen McGladeMcCulloh, and Steve Young for critical comments on the manuscript.

Correspondence may be addressed to Dr. Kathleen A. French, Department of Biology B-022, UCSD, La Jolla, CA 92093, her present address.

Copyright (C) 1986 Society for Neuroscience $0270-6474 / 86 / 020318-07 \$ 02.00 / 0$
}

microelectrodes in a single experiment (e.g., Elliott and Muller, 1983; Jansen and Nicholls, 1972; Wallace et al., 1977). In morphological studies, regenerating neurons and their targets have been injected with separate markers to indicate where varicosities in the two cells appear to touch, since varicosities are thought to be the sites of synapses (Macagno et al., 1985). As in electrophysiological experiments, these morphological techniques allow the study of only a few target neurons. The complexity of the neuropile has rendered even electron microscopy unsuccessful in determining whether inappropriate contacts are made during regeneration.

Mechanosensory neurons do, however, make one set of contacts in the CNS that can be viewed readily and in its entirety with the LM. The nociceptive sensory neurons ( $\mathrm{N}$ cells) synapse with particular targets in the neuropiles of their own ganglion and of adjacent ganglia (Elliott and Muller, 1983; Jansen et al., 1974; Muller and McMahan, 1976; Muller and Nicholls, 1974; Nicholls and Purves, 1970). In addition, they form baskets of processes around the somata of certain neurons in adjacent ganglia (Johansen et al., 1984; Muller et al., 1978), and these wrappings can easily be seen. Axosomatic contacts have been described in other invertebrates, where they evidently can be sites of synapses in the adult (Shkolnik and Schwartz, 1980; Zs.Nagy and Sakharov, 1969), and in some instances occur transiently during embryonic development (Macagno, 1981; Schacher et al., 1979; Taghert et al., 1982). The aims of this study with intracellularly injected HRP were to characterize further the N cell wrappings of somata in adjacent ganglia and to test during regeneration not only whether normal targets were contacted, but whether "mistakes" were made that might suggest how a regenerating neuron selects its targets.

\section{Materials and Methods}

\section{Maintenance and operations}

Leeches (Hirudo medicinalis) were obtained from suppliers in France and Germany and were maintained at $15^{\circ} \mathrm{C}$ in artificial spring water (see Appendix C, Muller et al., 1981). Animals were anesthetized with $8 \%$ ethanol in spring water, and small incisions were made in the ventral midbody region superficial to the nerve cord. Either the cord was crushed with fine forceps or one of the two connectives was cut after the surrounding blood sinus was opened. Animals were allowed to recover under standard maintenance conditions. The time between injury and the rest of the experiment varied from 6 weeks to longer than a year. Survival of this treatment was greater than $99 \%$.

\section{Physiological recordings}

In some experiments, short chains of ganglia were removed from the animal and were placed in a chamber that permitted rapid changes of bath solution, from normal leech saline $(115 \mathrm{~mm} \mathrm{NaCl}, 4 \mathrm{mM} \mathrm{KCl}, 2$ $\mathrm{mM} \mathrm{CaCl}_{2}$, and $10 \mathrm{~mm}$ Tris maleate, $\mathrm{pH}$ 7.4) to saline containing elevated $\left[\mathrm{Ca}^{2+}\right]$ and $\left[\mathrm{Mg}^{2+}\right](82 \mathrm{~mm} \mathrm{NaCl}, 4 \mathrm{mM} \mathrm{KCl}, 15 \mathrm{~mm} \mathrm{CaCl}, 18$ mм $\mathrm{MgCl}_{2}$, and $10 \mathrm{~mm}$ Tris maleate, $\mathrm{pH}$ 7.4), which can block poly- 

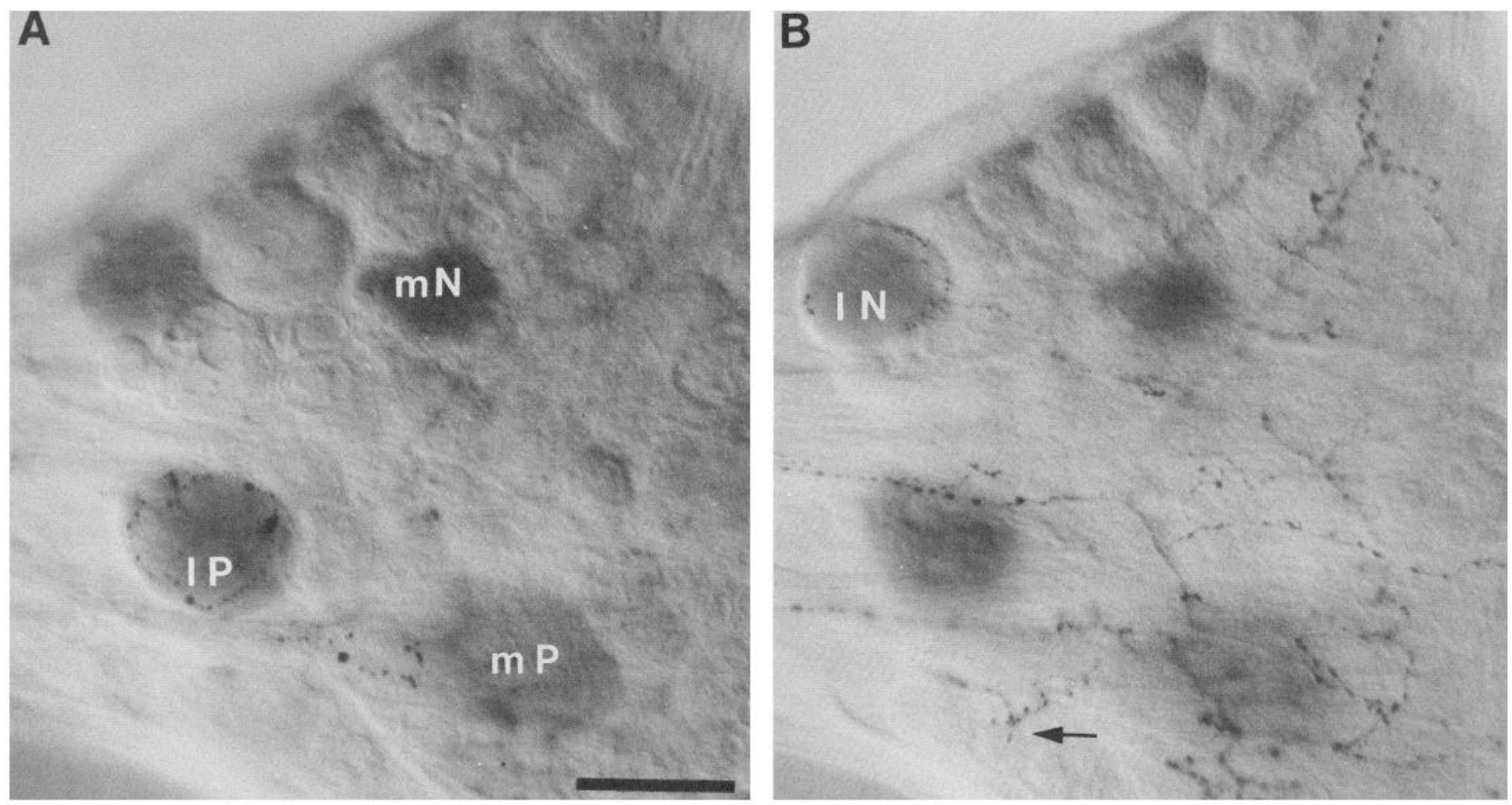

Figure 1. Axosomatic contacts made by an HRP-filled lateral $\mathrm{N}$ cell on three mechanosensory neurons in the anterior adjacent ganglion. The figure shows one side of the ganglion at two different planes of focus, with the anterior at the top. $\mathrm{N}$ and $\mathrm{P}$ cell somata were marked by injection of Procion navy blue prior to fixation. $A$, Processes wrapping medial (out of focus) and lateral $\mathrm{P}$ cells. The medial $\mathrm{N}$ cell was not wrapped in this ganglion. B, Different plane of focus showing processes in the neuropile and processes forming a basket around the lateral N cell's soma. Arrow points to a cell in the posterior cell packet that was wrapped in several regenerated ganglia, but only once in 120 ganglia from 45 normal leeches. $m P$, medial $\mathrm{P}$ cell; $l P$, lateral $\mathrm{P}$ cell; $m N$, medial $\mathrm{N}$ cell; $l N$, lateral $\mathrm{N}$ cell. Calibration bar, $50 \mu \mathrm{m}$.

synaptic connections mediated by an excitable interneuron. Signals elicited in several identified neurons by stimulating $\mathrm{N}$ cells were recorded with conventional apparatus (see Appendix C, Muller et al., 1981). The potentials were averaged using a Dagan model 4800 signal averager and were recorded on magnetic tape with a Vetter model D tape recorder; each sweep was visually monitored to rule out the presence of large events that could have biased the average.

\section{Intracellular labeling}

To determine the extent of their axonal projections into adjacent ganglia, $\mathrm{N}$ cells were marked by intracellular HRP-injection (Elliott and Muller, 1983). Cells from control and experimental leeches were labeled in the same manner. A chain of ganglia, which included the injured connective in experimental animals, was removed from the leech and placed in organ culture in modified Leibowitz- 15 medium. A $2 \%$ solution of HRP in $0.2 \mathrm{M} \mathrm{KCl}$ and $0.2 \%$ Fast Green FCF was pressure-injected into one or both of the lateral $\mathrm{N}$ cells in the ganglion just posterior to the injured connective. The preparation was then maintained in culture medium at $15^{\circ} \mathrm{C}$ for $2-3 \mathrm{~d}$ to allow the HRP to spread throughout the processes of the cell.

Next, potential target cells were marked. All of the N cells and pressure (P) sensory neurons in the anterior and posterior ganglia adjacent to the one containing the HRP-labeled somata were positively identified based on their distinctive action potentials and their positions within the ganglia, and they were injected with a $4 \%$ solution of Procion navy blue under pressure through the recording micropipette. Procion navy blue was chosen because it could be fixed, it contrasted well with HRP reaction product, and it remained localized to the soma after injection. Immediately afterwards, the preparations were fixed for $30 \mathrm{~min}$ at room temperature in $1.6 \%$ glutaraldehyde, $0.8 \%$ paraformaldehyde, and $5 \mathrm{~mm}$ $\mathrm{CaCl}_{2}$ in $0.1 \% \mathrm{M}$ sodium cacodylate buffer, $\mathrm{pH} 7.4$ (Muller and Carbonetto, 1979). Tissue was then processed with 3,3'-diaminobenzidine and $\mathrm{H}_{2} \mathrm{O}_{2}$ as substrates for the HRP, and it was mounted whole between coverslips, as previously described (Elliott and Muller, 1983; Muller and McMahan, 1976). Contrast was enhanced and depth of focus reduced by viewing most preparations with Nomarski interference optics.

\section{Electron microscopy}

For electron microscopy, tissue was prepared as above, except that (1) cells were not injected with Procion navy blue and (2) fixed tissue was postfixed with osmium, stained en bloc with cold uranyl acetate, and embedded in Epon 812 (Muller and McMahan, 1976). Then, $2 \mu \mathrm{m}$ sections were cut. Thick sections that contained varicosities were reembedded and were thin-sectioned. Thin sections were stained with lead before viewing them in a Jeol JEM100S electron microscope equipped with a eucentric goniometer.

\section{Results}

\section{Distribution and targets of somatic wrappings}

The axons of lateral $\mathrm{N}$ cells wrapped the somata of cells in adjacent anterior (Fig. 1) and posterior ganglia. Medial N cells also wrapped the somata of cells in adjacent ganglia, but they contacted fewer cells than did lateral $\mathrm{N}$ cells, so only lateral $\mathrm{N}$ cells are considered for the remainder of this paper. The number of cells wrapped by each $\mathrm{N}$ cell varied from preparation to preparation (Fig. $2 A$ ), even within a single leech. However, most $\mathrm{N}$ cells made three or four such baskets of processes in each adjacent ganglion. Most of the wrapped cells were ipsilateral to the filled cell, but contralateral cells were also wrapped. Occasionally, an $\mathrm{N}$ cell was seen to wrap cells two ganglia away from its soma. No somata within the ganglion containing the $\mathrm{N}$ cell's soma were wrapped.

To test the hypothesis that the wrapped somata were chiefly $\mathrm{P}$ and $\mathrm{N}$ sensory cells, as was suspected in earlier studies (Johansen et al., 1984; Muller et al., 1978), all of the N and P cells in the two ganglia adjacent to the HRP-injected cell were filled with Procion navy blue after they had been identified by their distinctive electrical activity. The wrapping of stained, identified cells and of unlabeled cells was then examined. As suspected, 
A
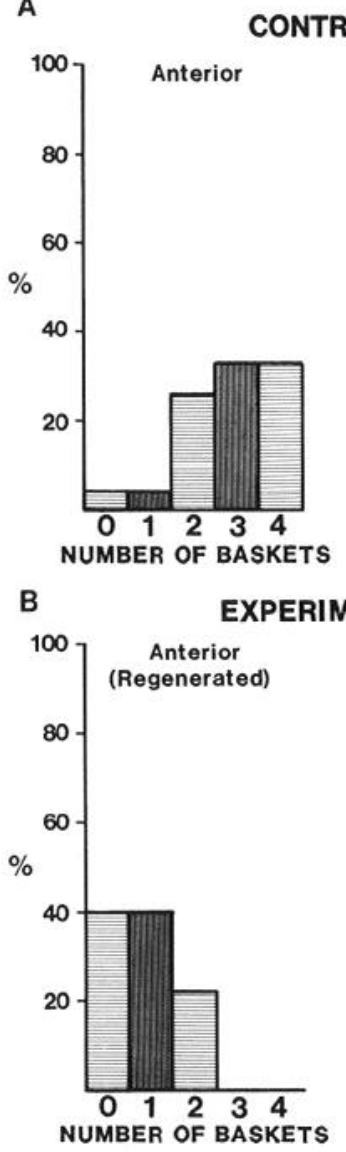

Figure 2. Number of ipsilateral axosomatic baskets made in adjacent ganglia by HRP-filled lateral $\mathrm{N}$ cells, expressed as a percentage of the number of filled lateral $\mathrm{N}$ cells. Some cells made no detectable contact; none contacted more than four ipsilateral somata in an adjacent ganglion. $A$, Contacts made by lateral N cells in the anterior and posterior adjacent ganglia in uninjured leeches. $B$, Contacts made in the anterior and posterior adjacent ganglia in experimental animals. The axons in the anterior connectives had been crushed or cut (see Methods) and were allowed from 6 weeks to more than a year to regenerate. The posterior axons were left intact.

most wrapped cells were either $\mathrm{N}$ or $\mathrm{P}$ cells, in both anterior and posterior ganglia (Figs. 1 and $3 A$ ). In segmental ganglia 714 of normal leeches, lateral $\mathrm{N}$ cells were most likely to wrap their ipsilateral homologs $(89 \%$ in the anterior adjacent ganglion) and the ipsilateral medial (85\%) and lateral (52\%) P cells. In only three of 54 ganglia did the lateral $\mathrm{N}$ cell wrap cells other than $\mathrm{N}$ or $\mathrm{P}$ cells. In those ganglia, one wrapped cell was a Leydig cell, one was a small unidentified cell near the lateral P cell, and one was a small cell at the extreme posterior margin of the ganglion (Fig. 1A; for maps of the ganglion see Appendix D of Muller et al., 1981).

\section{Are axosomatic contacts synapses?}

The morphology of the axosomatic contacts viewed with light microscopy suggests that they might be synaptic sites. Within the neuropile, varicosities along sensory neuron processes are sites of synaptic contact with other neurons (Muller and McMahan, 1976), and lateral $\mathrm{N}$ cells make such contacts within the neuropile of adjacent ganglia. $\mathrm{N}$ cell processes that form baskets around somata are also varicose, suggesting that they might be making synapses, but most of the varicosities are smaller than the $5 \mu \mathrm{m}$ enlargements typical of synapses in the neuropile.
A

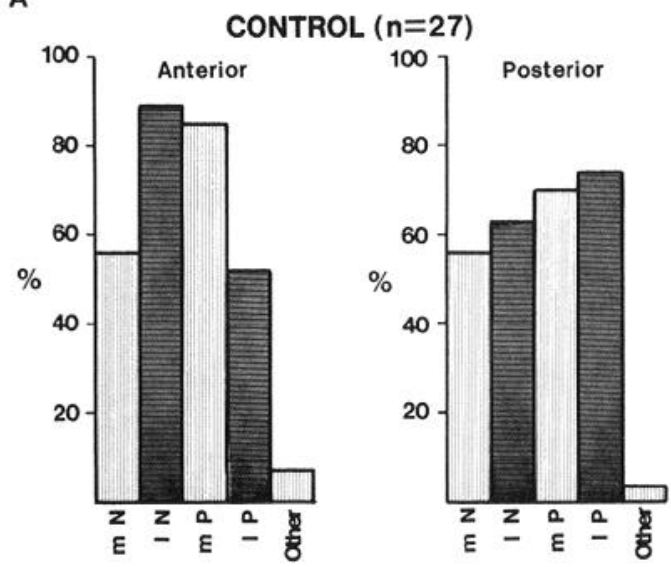

B

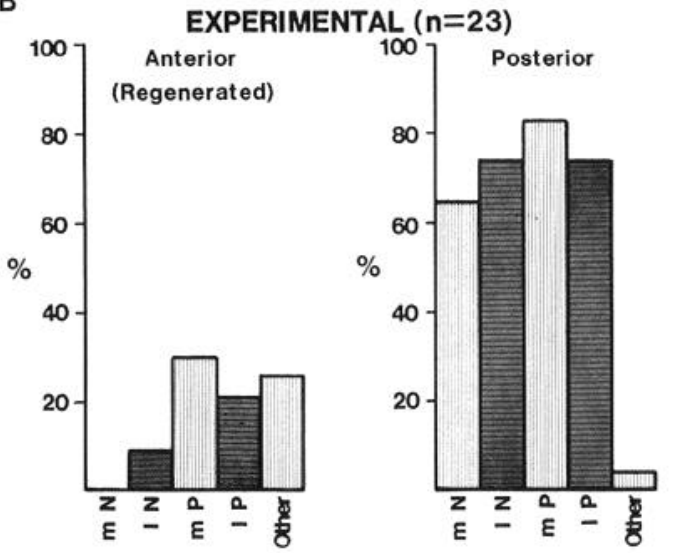

Figure 3. Percent of HRP-filled lateral $\mathrm{N}$ cells contacting the somata of identified ipsilateral cells in adjacent ganglia. $A$, Somatic contacts in the anterior and posterior adjacent ganglia in normal leeches. $B$, Somata contacted in experimental animals. Anterior processes were crushed or cut and allowed to regenerate. Posterior processes remained intact. The contacts made by regenerated axons on Other cells in the anterior ganglia were all made on a small cell at the lateral margin of the posterior cell packet of the ganglion, in the same position as that marked with an arrow in Figure $1 A . m N$, medial $\mathrm{N}$ cell; $l N$, lateral $\mathrm{N}$ cell; $m P$, medial $\mathrm{P}$ cell; $l P$, lateral $\mathrm{P}$ cell; $O t h e r$, any other ipsilateral cell in the ganglion.

Electron micrographs of HRP-filled $\mathrm{N}$ cell axons that wrap somata showed that the axons penetrated the glial sheath and that these processes directly apposed the somata (Fig. 4). In 11 varicosities examined, there were mitochondria and typically a few pleiomorphic vesicles, but hallmarks of the chemical synapses seen in the neuropile, such as clusters of vesicles and a synaptic cleft of uniform width (Muller, 1979), were absent. This lack is not conclusive because in many systems some synapses do not have a uniform synaptic cleft and certain other synaptic specializations (e.g., Geffen and Livett, 1971). We also looked for evidence of electrical synapses, but there was no area of uniformly narrow separation between the membranes of the target cell soma and those of the filled processes that would suggest an electrical synapse (Muller and Carbonetto, 1979). Profiles of other, unstained axons were sometimes visible near the stained profiles, and at such sites neither the unstained axons nor the cell body contained synaptic structures. What is the function of these axosomatic contacts if they are not conventional synapses?

Electrophysiological recordings from the ipsilateral N, P, and Leydig cells in ganglia adjacent to a lateral $\mathrm{N}$ cell showed that single action potentials in the $\mathrm{N}$ cell evoked synaptic potentials as large as $2 \mathrm{mV}$ in these cells, even in solutions containing 


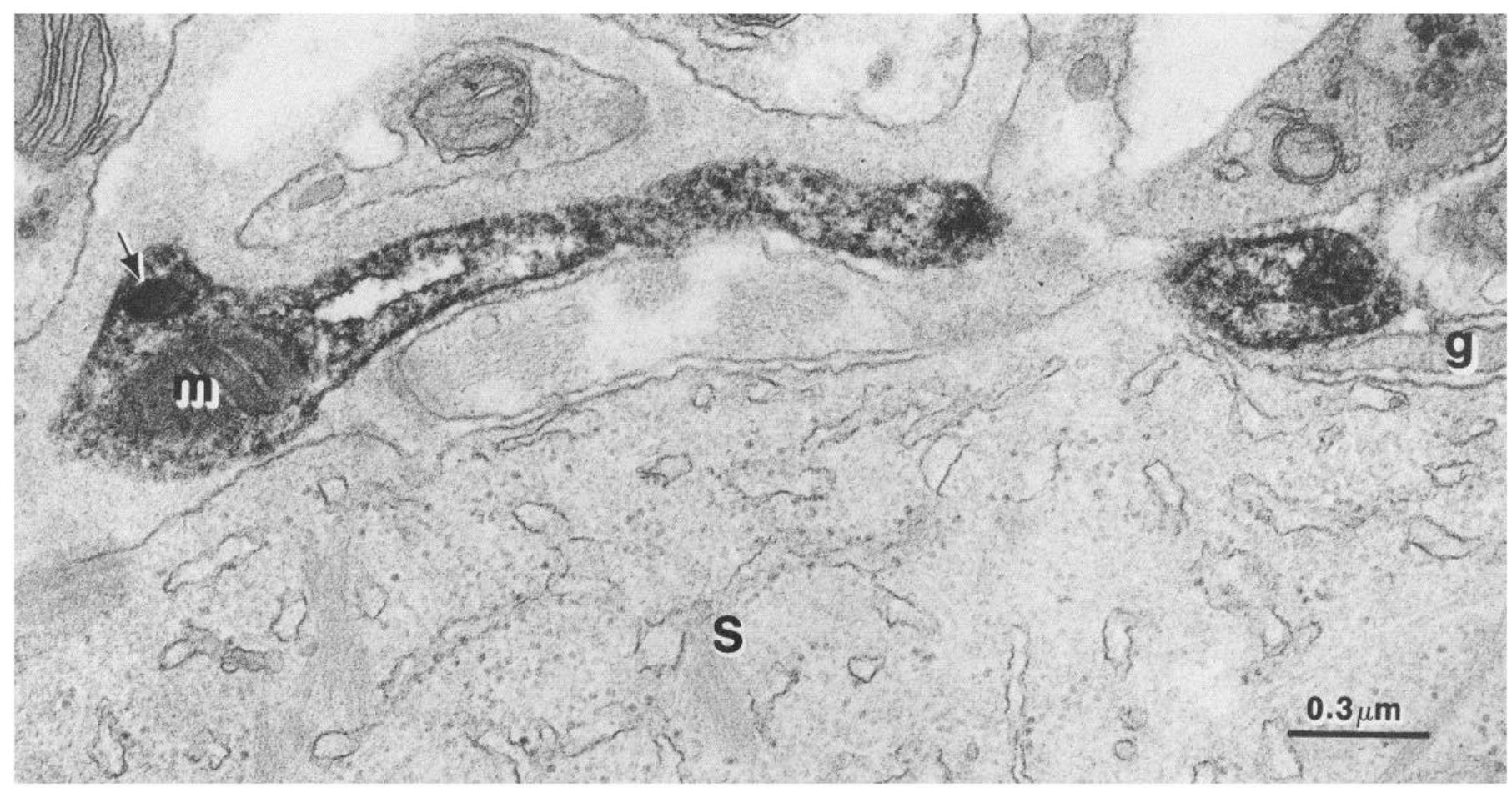

Figure 4. Electron micrograph of dark, HRP-filled processes of an N cell wrapping the soma $(S)$ of a cell in the adjacent ganglion. The section included portions of a varicosity, containing a mitochondrion $(M)$ and dense core vesicles (arrow), and of a glial cell $(G)$. Another process of the glial cell apparently lies between part of a filled process and the target cell's soma. Neither this nor other somatic contacts made by $\mathrm{N}$ cells appeared to be synaptic, based on conventional criteria.

elevated $\left[\mathrm{Ca}^{2+}\right]$ and $\left[\mathrm{Mg}^{2+}\right]$ (see, for example, Fig. 5). This result indicated that the connections between the $\mathrm{N}$ cell and these cells were monosynaptic. It could not, however, distinguish between contacts on the soma and those restricted to the neuropile, such as those that excite the L cell (Jansen et al., 1974) and the AP cell (also known as the Anterior Pagoda and the Debby cell; Muller et al., 1981; Sunderland, 1980), cells that are not wrapped by $\mathrm{N}$ cell processes.

Further physiological evidence indicated that contacts made by way of the baskets do synaptically depolarize the wrapped cell. Scott and Muller (Muller et al., 1978) found that removing the glial sheath around $\mathrm{P}$ and $\mathrm{N}$ cell somata also removed their $\mathrm{N}$ cell baskets. Stimulating an $\mathrm{N}$ cell and recording synaptic potentials in an uninjured postsynaptic cell before and after the glial sheath was removed should, therefore, have indicated any contribution made by the axosomatic contacts. Figure 5 shows an example of the results obtained in four similar experiments. Apparently, the baskets contribute a rapidly rising component of the synaptic potential. The results of this experiment and others in which the input resistance of the postsynaptic cell rose after desheathing are consistent with the hypothesis that the baskets may be sites of transmission. The axonal baskets contact the soma, so such sites would be electrically closer to a recording electrode than are synapses that are between the same cells but located in the neuropile. Changing membrane potential by injecting current into the postsynaptic cell showed that the increased input resistance after desheathing was not due to the 6 $\mathrm{mV}$ more negative resting membrane potential after desheathing; the resistance was as high as it was at depolarized voltages.

A useful control was the synaptic potential in the AP cell next to and in the same glial sheath as the postsynaptic $\mathrm{N}$ cell. When the ganglion was desheathed, leaving the input resistance of the AP cell unchanged and the resting potential the same to within $5 \%$, the amplitude of the synaptic signal from the stimulated $\mathrm{N}$ cell did not change. Furthermore, no initial rapid component of the synaptic potential was lost. This result is consistent with our observation that there are no $\mathrm{N}$ cell baskets around the AP cell soma.

\section{Independent incidence of wrappings}

As background for planned regeneration studies, it seemed worthwhile to know whether an N cell's wrapping of any given cell was independent of its wrapping of others. Must an N cell wrap one particular cell before it can wrap another? Is there a mutual exclusion such that two particular cells tend to not both be wrapped? Chi-square analysis of the control data indicated that there was no interdependence between an N cell's wrapping any one cell and its wrapping any other $(p>0.10$ for all possible pairs of cells).

\section{Regeneration of somatic contacts}

The lateral $\mathrm{N}$ cells just posterior to each injured connective were filled with HRP. This arrangement left the posterior process of the filled cell intact, allowing the possibility that it could serve as an internal control. Comparing the somatic contacts made by the posterior processes in control and experimental animals shows that the pattern of wrapping was essentially the same in the two groups (Figs. 2 and 3). Comparing the contacts made by the anterior processes in control and experimental groups reveals that regenerated processes approximate, but do not replicate, the wrappings in intact preparations. Of 72 injured $\mathrm{N}$ cells, 23 grew processes into the ganglion anterior to the injured connective. In 14 of these, at least one cell soma was wrapped by the regenerated processes (Fig. $2 B$ ). The fraction of cells that regenerated axosomatic contacts $(19 \%)$ is almost identical with that observed by Elliott and Muller (1983), who used physiological methods to study regeneration of $\mathrm{P}$ and $\mathrm{N}$ cell contacts with the $\mathrm{L}$ motor neuron.

The regenerated baskets tended to be simpler than normal in two ways. First, fewer cells than usual were wrapped by the 
Figure 5. Synaptic potentials produced in the lateral $\mathrm{N}$ cell of the anterior adjacent ganglion $\left(N_{7}\right)$ by action potentials generated in a lateral $\mathrm{N}$ cell $\left(N_{8}\right)$ on the same side of the CNS. After desheathing $\mathrm{N}_{7}$, the synaptic potential from $\mathrm{N}_{\gamma}$ diminished, but the cell's input resistance doubled, from 50 to $100 \mathrm{M} \Omega$, and its resting potential shifted from -35 to $-41 \mathrm{mV}$. The resting potential of $\mathrm{N}_{8}$ remained -38 $\mathrm{mV}$ during this time. $\mathrm{N}_{8}$ was stimulated at $0.5 \mathrm{~Hz}$. Recordings were made in high $\left[\mathrm{Ca}^{2+}\right]$, high $\left[\mathrm{Mg}^{2+}\right]$ saline (see Methods). Signals shown are averages of 32 sweeps, each of which produced a synaptic potential.

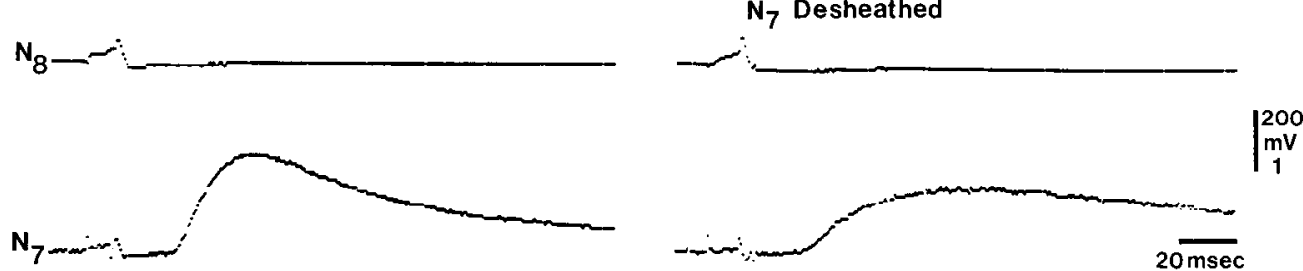

regenerated processes (Fig. 2). Second, although the amount of rcgencration varied, the rcgencratcd wrappings were usually lcss extensive and less branched than were controls (Fig. 6), with rare exceptions (e.g., top of Fig. $6 B$ ). When leeches that had been maintained for many months after injury were compared with those that had been allowed only 6 weeks for recovery, there appeared to be no relationship between complexity of wrapping and time for regeneration. Apparently regeneration of the axosomatic contacts was essentially complete after 6 weeks and neither expanded nor contracted when more time was allowed.

The cell most often wrapped by regenerating axons of the lateral $\mathrm{N}$ cell was the medial $\mathrm{P}$ cell (Fig. $3 B$ ), one of the cells most likely to be contacted in normal leeches. However, a novel cell was also consistently wrapped by regenerating $\mathrm{N}$ cells. In six of the 14 preparations in which at least one soma was contacted by a regenerated axon, a cell at the lateral margin of the posterior cluster of neurons was wrapped (Fig. 7). In 120 ganglia from unoperated leeches, this unusual wrapping was seen only once (in the ganglion shown in Fig. 1). The regeneration of the lateral $\mathrm{N}$ cell's somatic contacts appears to be selective, but the selectivity is somewhat different from that in normal leeches.

The pathways taken by normal and regenerating $\mathrm{N}$ cell axons that wrapped somata in the anterior adjacent ganglia were similar. Axons tended to follow the tissue delineating the margins of the cell clusters or packets within the ganglion (Fig. 1). Processes that formed baskets around somata branched off near the wrapped soma, often climbing its axon hillock, then wrapped the cell and ended. They did not appear to extend further. Certain details of the pathways were found consistently. For example, the medial $P$ cell was always wrapped from its throat up to the more bulbous region of the soma, whether the wrapping axon was an intact control or a regenerated process (Figs. 1 and
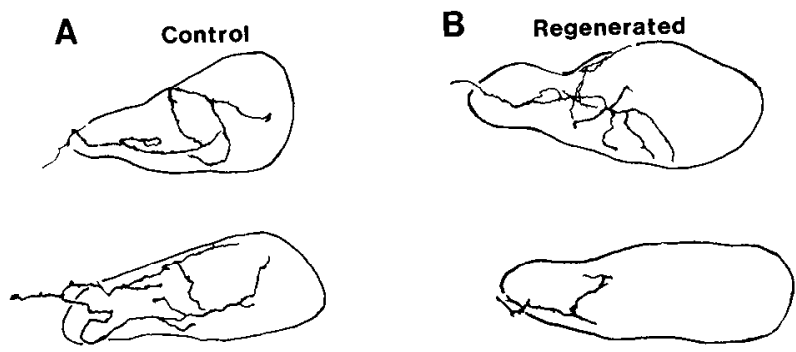

Figure 6. Camera lucida drawings of axosomatic baskets made by HRP-filled lateral $N$ cells on medial $P$ cells in the anterior adjacent ganglion. $A$, Baskets in control animals. $B$, Regenerated baskets. The wrapping of the top cell was unusually elaborate for regenerated processes. The simpler wrapping of the bottom cell was more typical of regenerated baskets. Calibration bar, $50 \mu \mathrm{m}$.
6). Some differences in pathway arose, because regenerated $\mathrm{N}$ cells often sent supcrnumcrary processes into the antcrior ganglion, and when several processes entered the ganglion, one of those nearest to the cell to be wrapped was the source of the branch that contacted the soma. In all cases, regenerated processes bypassed several cells before turning and contacting the soma that would be wrapped, clearly indicating some process of selection.

\section{Discussion}

The lateral $\mathrm{N}$ cells in leech midbody ganglia form baskets of processes around the somata of several mechanosensory cells in the adjacent anterior and posterior ganglia, while not wrapping the somata of other cells, such as the touch (T) sensory cells, the AP neurons, or the $\mathrm{L}$ motor neurons. Physiological experiments suggested that the baskets excite the wrapped somata.

Because all of the axosomatic contacts made by a cell are readily visible, observing their regeneration has made it possible for the first time to assess directly the completeness and accuracy of regeneration of a set of contacts in the leech CNS. Morphological observations showed that somatic contacts were regenerated after the connectives linking ganglia were injured, but the baskets occurred less often and with a somewhat simpler structure than in normal leeches. This result is consistent with the results of other studies of mechanosensory cell regeneration. Physiological experiments have shown that $\mathrm{N}$ cells reconnect with normal synaptic targets after lesions similar to those described in this paper, but do so incompletely (Elliott and Muller, 1983), as do other sensory cells in leeches (Muller and Nicholls, 1981). Other work has shown that physiological reconnection between particular T cells, like morphological repair, is usually incomplete even after many months (Macagno et al., 1985). In previous physiological studies, some sensory synapses were functionally reestablished more readily than others, but no definite misconnections could be found.

In contrast, the morphological studies reported here showed a striking change in selectivity after regeneration: Regenerated processes often wrapped a cell located at the lateral margin of the posterior cell packet, one that was only very rarely contacted by normal $\mathrm{N}$ cells. Little is known about this lateral posterior cell except that the position of the wrapped cell was the same in all seven preparations (one control, six experimental) in which it was seen. This constant position is the only evidence that the same cell was wrapped in all seven ganglia. Normal N cell processes pass near the location of this cell, but it has not been characterized physiologically. It would be interesting to know the cell's connections, its development, and the transmitter receptors on its membrane, because this information might provide clues as to why it is attractive to regenerating $N$ ccll processes, while it apparently is not so to the processes of embryonic $\mathrm{N}$ cells. It is not known, for example, whether during embryonic 


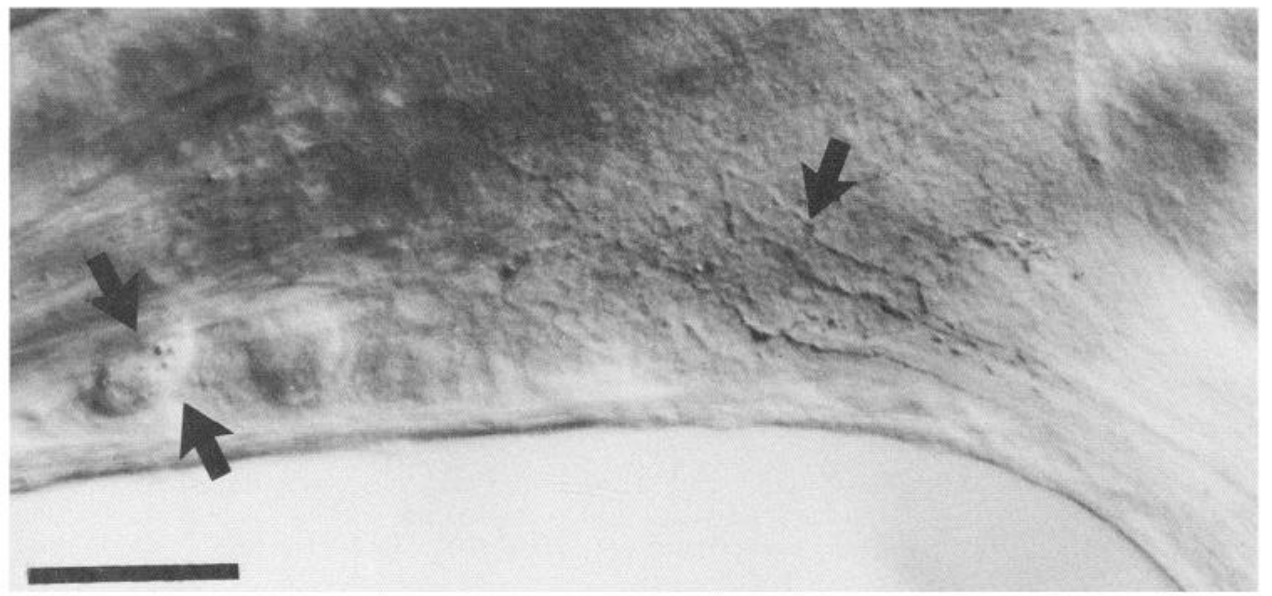

Figure 7. Regenerated lateral $\mathrm{N}$ cell process making axosomatic contact with a posterolateral cell in the anterior adjacent ganglion. This cell was in the same position as the cell marked by an arrow in Figure $1 A$. Single arrow indicates multiple regenerated processes entering the ganglion from the connective. Double arrowheads point out the posterolateral cell contacted by a regenerated process in this ganglion. Anterior is toward the top; lateral, the left. Calibration bar, $50 \mu \mathrm{m}$.

development the cell is contacted transiently or is in a less favorable position.

In regeneration, there is evidence in the leech that some axons regenerate preferentially along severed distal stumps (Macagno et al., 1985; Muller and Carbonetto, 1979) and in some cases synapse with (Carbonetto and Muller, 1977) or rejoin (DeRiemer et al., 1983; Van Essen and Jansen, 1977) them. However, rejoining the distal stump does not seem to be a significant mechanism for axon regeneration by $\mathrm{N}$ cells (Elliott and Muller, 1983), and the following lines of evidence suggest that the distal stump played, at most, a limited role in the regeneration of baskets. Regenerating $\mathrm{N}$ cells often sent several processes into the anterior ganglion, rather than the usual one. The pattern of regenerated wrappings was simpler, and they contacted fewer cells than those in normal leeches. Of the cells usually wrapped, the one closest to growing processes (medial P) was contacted most often, rather than the ipsilateral homolog, and a new cell was frequently wrapped by regenerating $\mathrm{N}$ cell processes.

Also shown in this study was that the medial and lateral $\mathrm{N}$ cells differ from one another, both in wrapping and in being wrapped. The medial $\mathrm{N}$ cells were targets for lateral $\mathrm{N}$ cell contacts less often than the other three cell types that were commonly wrapped. They, in turn, were less consistent than lateral $\mathrm{N}$ cells in forming such contacts on other cells. Understanding the basis of the difference in somatic contacts between the two types of nociceptive cells might clarify the functions of their wrappings.

Other differences between medial and lateral $\mathrm{N}$ cells are known, such as their sensitivity to possible transmitters (Sargent et al., 1977). They have different peripheral targets, and only the lateral $\mathrm{N}$ cells wrap the somata of putative stretch receptors in the periphery (Blackshaw et al., 1982). Furthermore, the two types of $\mathrm{N}$ cells differ in certain antigenic (Hogg et al., 1983) and pharmacological (Johansen et al., 1984) properties. The difference in their pattern of axosomatic contacts provides yet another piece of evidence that neurons of the same sensory modality may, in fact, differ greatly in their cell biology.

Morphological examination of varicosities along the somatic baskets failed to produce signs that they contain conventional synapses. However, the baskets are accurately regenerated, and they resemble-at least superficially - somatic contacts that apparently are the sites of synapses in other invertebrates. This morphology and the physiological results suggest that they are not simply vestigial. Physiological experiments in normal preparations indicated that the wrapped cells receive monosynaptic connections from the lateral $\mathrm{N}$ cell. At least a portion of the synaptic signal seemed to be mediated by the baskets, but the nature and extent of communication between the soma and its wrappings are unknown. The somata of many neurons in the leech, including the $\mathrm{P}$ and $\mathrm{N}$ sensory neurons, are exquisitely sensitive to certain locally applied transmitters (Sargent et al., 1977), and individual sensory neurons plated in tissue culture medium together with other leech neurons can receive synapses directly on their cell bodies from the other neurons (Fuchs et al., 1982). Moreover, in some systems such as the vertebrate retina, there is evidently nonvesicular release of neurotransmitters at synapses (Schwartz, 1982). It is, therefore, conceivable that lateral $\mathrm{N}$ cells affect the behavior of their target sensory cells by releasing transmitter by some such unconventional mechanism.

The basic conclusions that can be drawn from the regeneration experiments do not require that these somatic contacts be synapses. The baskets of processes, visible in whole-mount with the LM, show that regeneration is highly selective. Those contacts that are unusual, like the aberrant connections occasionally made by regenerating cockroach motor neurons (Whitington, 1979) and persistent changes in connections following CNS lesions in the leech (Jansen et al., 1974), arise consistently and may reflect differences between the developing and the regenerating nervous system in timing, state of differentiation of the targets, or spatial arrangements.

\section{References}

Baylor, D. A., and J. G. Nicholls (1971) Patterns of regeneration between individual nerve cells in the central nervous system of the leech. Nature 232: 268-270.

Blackshaw, S. E., J. G. Nicholls, and I. Parnas (1982) Physiological responses, receptive fields, and terminal arborizations of nociceptive cells in the leech. J. Physiol. (Lond.) 326: 251-260.

Carbonetto, S., and K. J. Muller (1977) A regenerating neurone in the leech can form an electrical synapse on its severed axon segment. Nature 267: 450-452.

DeRiemer, S. A., E. J. Elliott, E. R. Macagno, and K. J. Muller (1983) Morphological evidence that regenerating axons can fuse with severed axon segments. Brain Res. 272: 157-161.

Elliott, E. J., and K. J. Muller (1983) Sprouting and regeneration of sensory axons after destruction of ensheathing glial cells in the leech central nervous system. J. Neurosci. 3: 1994-2006.

Fuchs, P. A., L. E. Henderson, and J. G. Nicholls (1982) Chemical transmission between individual Retzius and sensory neurons of the leech in culture. J. Physiol. (Lond.) 323: 195-210.

Geffen, L. B., and B. G. Livett (1971) Synaptic vesicles in sympathetic neurons. Physiol. Rev. 51: 98-157.

Hogg, N., M. Flaster, and B. Zipser (1983) Cross-reactivities of monoclonal antibodies between select leech neuronal and epithelial tissues. J. Neurosci. Res. 9: 445-457.

Jansen, J. K. S., and J. G. Nicholls (1972) Regeneration and changes in synaptic connections between individual nerve cells in the central nervous system of the leech. Proc. Natl. Acad. Sci. USA 69: 636639.

Jansen, J. K. S., K. J. Muller, and J. G. Nicholls (1974) Persistent modification of synaptic interactions between sensory and motor nerve 
cells following discrete lesions in the central nervous system of the leech. J. Physiol. (Lond.) 242: 289-305.

Johansen, J., S. Hockfield, and R. D. McKay (1984) Distribution and morphology of nociceptive cells in the CNS of three species of leeches. J. Comp. Neurol. 226: 263-273.

Johansen, J., J. Yang, and A. Kleinhaus (1984) Actions of procaine on specific nociceptive cells in leech central nervous system. J. Neurosci. 4: 1253-1261.

Macagno, E. (1981) Cellular interactions and pattern formation in the development of the visual system of Daphnia magna (Crustacea, Branchiopoda). II. Induced retardation of optic axon ingrowth results in a delay in laminar neuron differentiation. J. Neurosci. 1:945-955.

Macagno, E., K. Muller, and S. DeRiemer (1985) Regeneration of axons and synaptic connections by touch sensory neurons in the leech CNS. J. Neurosci. 5: 2510-2521.

Muller, K. J. (1979) Synapses between neurones in the central nervous system of the leech. Biol. Rev. 54: 99-134.

Muller, K. J., and S. Carbonetto (1979) The morphological and physiological properties of a regenerating synapse in the CNS of the leech. J. Comp. Neurol. 185: 485-516.

Muller, K. J., and U. J. McMahan (1976) The shapes of sensory and motor neurons and the distribution of their synapses in ganglia of the leech: A study using intracellular injection of horseradish peroxidase. Proc. R. Soc. Lond. [Biol.] 194: 481-499.

Muller, K. J., and J. G. Nicholls (1974) Different properties of synapses between a single sensory neurone and two different motor cells in the leech CNS. J. Physiol. (Lond.) 238: 357-369.

Muller, K., and J. Nicholls (1981) Regeneration and plasticity. In The Neurobiology of the Leech, K. Muller, J. Nicholls, and G. Stent, eds., pp. 197-226, Cold Spring Harbor Laboratory, NY.

Muller, K. J., J. G. Nicholls, and G. S. Stent (eds.) (1981) Neurobiology of the Leech, Cold Spring Harbor Laboratory, NY.

Muller, K. J., S. A. Scott, and B. E. Thomas (1978) Specific associations between sensory cells. In Carnegie Institution Year Book 77, pp. 6970 .
Nicholls, J. G., and D. Purves (1970) Monosynaptic chemical and electrical connexions between sensory and motor cells in the central nervous system of the leech. J. Physiol. (Lond.) 209: 647-667.

Sargent, P. B., K.-W. Yau, and J. G. Nicholls (1977) Extrasynaptic receptors on cell bodies of neurons in the central nervous system of the leech. J. Neurophysiol. 40: 446-452.

Schacher, S., E. R. Kandel, and R. Wooley (1979) Development of neurons in the abdominal ganglion of Aplysia californica I. Axosomatic synaptic contacts. Dev. Biol. 71: 163-175.

Schwartz, E. A. (1982) Calcium-independent release of GABA from isolated horizontal cells of the toad retina. J. Physiol. (Lond.) 323: 211-227.

Shkolnik, L. J., and J. Schwartz (1980) Genesis and maturation of serotonergic vesicles in identified giant cerebral neuron of Aplysia. J. Neurophysiol. 43: 945-967.

Sunderland, A. J. (1980) A hitherto undocumented pair of neurons in the segmental ganglion of the leech which receive synaptic input from mechanosensory cells. Comp. Biochem. Physiol. [A] 67: 299302.

Taghert, P. H., M. J. Bastiani, R. K. Ho, and C. S. Goodman (1982) Guidance of pioneer growth cones: Filopodial contacts and coupling revealed with an antibody to Lucifer yellow. Dev. Biol. 94: 391-399.

Van Essen, D. C., and J. K. S. Jansen (1977) The specificity of reinnervation by identified sensory and motor neurons in the leech. $J$. Comp. Neurol. 171: 433-454.

Wallace, B. G., M. Adal, and J. G. Nicholls (1977) Regeneration of synaptic connexions of sensory neurones in leech ganglia in culture. Proc. R. Soc. Lond. [Biol.] 199: 567-585.

Whitington, P. M. (1979) The specificity of innervation of regenerating motor neurons in the cockroach. J. Comp. Neurol. 186: 465-472.

Zs.-Nagy, I., and D. A. Sakharov (1969) Axo-somatic synapses in procerebrum of Gastropoda. Experientia 25: 258-259. 